\title{
Progression of Soot Cake Layer Properties During the Systematic Regeneration of Diesel Particulate Filters Measured with Neutron Tomography
}

\author{
Todd J. Toops • Josh A. Pihl • Charles E. A. Finney • \\ Jens Gregor • Hassina Bilheux
}

Received: 3 November 2014 /Revised: 5 December 2014 / Accepted: 7 December 2014 / Published online: 16 January 2015

(C) Springer SIP, AG (outside the USA) 2015

\begin{abstract}
Although particulate filters (PFs) have been a key component of the emission control system for modern diesel engines, there remain significant questions about the basic regeneration behavior of the filters and how it changes with accumulation of increasing soot layers. This effort describes a systematic deposition and regeneration of particulate matter in $25-\mathrm{mm}$ diameter $\times 76$-mm long wall-flow PFs composed of silicon carbide (SiC) material. The initial soot distributions were analyzed for soot cake thickness using a nondestructive neutron imaging technique. With the PFs intact, it was then possible to sequentially regenerate the samples and reanalyze them, which was performed after nominal 20,50 , and $70 \%$ regenerations. The loaded samples show a relatively uniform distribution of particulate with an increasing soot cake thickness and nearly identical initial density of $70 \mathrm{mg} / \mathrm{cm}^{3}$. During regeneration, the soot cake thickness initially decreases significantly while the density increases to $80-90 \mathrm{mg} / \mathrm{cm}^{3}$. After $\sim 50 \%$ regeneration, the soot cake thickness stays relatively constant, but instead, the density decreases as pores open up in the layer $\left(\sim 35 \mathrm{mg} / \mathrm{cm}^{3}\right.$ at $70 \%$ regeneration). Complete regeneration initially occurs at the rear of the PF channels. With this information, a conceptual model of the regeneration is proposed.
\end{abstract}

Keywords Particulate filter · Soot cake properties · Neutron imaging $\cdot$ Soot oxidation $\cdot$ Regeneration

\footnotetext{
T. J. Toops $(\bowtie) \cdot$ J. A. Pihl $•$ C. E. A. Finney $\cdot$ H. Bilheux Oak Ridge National Laboratory, Oak Ridge, TN, USA

e-mail: toopstj@ornl.gov

J. Gregor

University of Tennessee, Knoxville, TN, USA
}

\section{Introduction}

High-efficiency lean burn combustion engines, such as those that run on diesel fuel, offer a promising strategy for reducing petroleum consumption. However, meeting increasingly stringent emission standards with lean burn engines has proven to be a challenge. To reduce the biologically and environmentally harmful particulate matter emitted by diesel-powered vehicles, stringent emission regulations were enacted in 2007. This led to the implementation of particulate filters (PFs, also known as diesel particulate filters, DPFs, in diesel vehicles) on every onroad diesel vehicle. Soot and other particulates are deposited in the PF as the engine exhaust gases flow through the porous filter wall and out the exhaust channels. Unfortunately, the implementation of emission control devices often results in a fuel penalty and erosion in the efficiency advantages of lean burn operation. Installation of the PF in the engine exhaust system introduces a flow restriction, which results in a small backpressure. As the PF traps soot, the backpressure increases. Excessive backpressure can result in increased fuel consumption or engine malfunction. Thus, the PF must be periodically regenerated to remove the trapped particulate. In many PF systems, regeneration is accomplished by heating the PF to temperatures at which the trapped soot is rapidly oxidized by the oxygen in the exhaust stream (a process termed "active" regeneration). While burning the soot out of the PF reduces the backpressure, $\mathrm{PF}$ heating is typically accomplished by injecting additional fuel in the exhaust. Active PF regeneration induces a fuel penalty which can exceed $4 \%$ of total fuel consumption [1]. However, the capture and regeneration processes are not well understood and thus not optimized for fuel economy. Specifically, it is not well known how soot is distributed in the PFs during loading, how this distribution changes during regeneration, and how much fuel is required to adequately regenerate the PFs. A common technique employed to estimate the amount of soot deposited in the PF is pressure differential; 
i.e., the pressure drop across the $\mathrm{PF}$ is assumed to be correlated to soot loading. As has been reported elsewhere [2-5] and will be shown again in this study, this approach can be significantly misleading when estimating the amount of soot remaining in the filter, and thus, a better understanding of soot distribution during the regeneration process is needed.

Typical methods of studying soot distribution as regeneration progresses employ destructive measurements that limit sequential studies of the devices while they are still functional. Additionally, the mechanical action of the cutting process can disturb the position and density of the soot layers and alter the materials being investigated. A nondestructive method for analyzing low-density depositions in PFs will provide new and valuable insights into the physical and chemical processes that occur during PF regeneration. Based on these motivations, our recent efforts have focused on the employment of a neutron imaging capability combined with computerized reconstructions of the recorded radiographs to achieve highquality representative 3-D data sets. This effort builds on our earlier studies that first described our techniques using neutrons to image PFs $[6,7]$, and it continues the investigation that was started by others [8-10].

In the present study, $25-\mathrm{mm}$ diameter $\times 76-\mathrm{mm}$ long wallflow PFs were loaded with varying amounts of particulate matter in engine exhaust and imaged with neutrons at several levels of regeneration. The PFs and the particulate are all hygroscopic, and the amount of ambient water that they adsorb is proportional to the accessible surface area. This water is the major contributor to neutron contrast in the images. While it can be possible to distinguish carbonaceous particulate/soot from cordierite due to the higher surface area of soot, we have illustrated that the contrast between silicon carbide ( $\mathrm{SiC}$ ) and soot is not as high; however, the contrast between soot and the air of an open channel is more than enough to determine soot layer thickness [7]. This is the basis of the analysis that we will perform in this study as we measure the progression of the soot layer thickness and density in a series of uncatalyzed $\mathrm{SiC}$ PFs that have been loaded to 3,5 , and $7 \mathrm{~g}$ of particulate per liter of filter. The goal of this research is twofold: first, to understand how the amount of soot loaded impacts the distribution of soot in the PFs and, second, to understand how sequential regeneration changes the soot distribution. The sequential regeneration of the filter will be stopped and the PFs imaged after burning approximately $20,50,70$, and $100 \%$ of the soot loaded on the PFs.

\section{Materials and Methods}

\subsection{PFs and Loading Techniques}

PFs consist of a monolith construction where the walls are porous and allow flow between channels. To force flow through the walls, the channels are alternately plugged, such that the inlet channels are open on the front end and plugged at the rear of the PF. Conversely, the exit channels are plugged on the front end and open at the rear of the PF. This geometry forces flow through the walls, and particulate is trapped in the inlet channels. Figure 1 highlights the unit cell of a given PF showing the alternating plugs in the front and rear cross section, as well as the open channels on the interior. The size, composition, and porosity of PFs can vary significantly depending on the application needs. Research-scale PFs ( $25 \mathrm{~mm}$ OD, $76 \mathrm{~mm}$ length) made of $\mathrm{SiC}$, cordierite, and aluminum titanate were employed in this study; some of the PF substrates were washcoated with an oxidation catalyst by a catalyst supplier, while others were left uncoated. All of the PF samples were loaded with soot in a slip stream pulled from the exhaust of an engine operated at steady state $(1950 \mathrm{rpm}, 475 \mathrm{~N} \mathrm{~m})$ on a dynamometer. The engine exhaust gas recirculation (EGR) was manually adjusted to achieve a filter smoke number (FSN) of 2.1, ensuring reasonable sample loading times. The sampling system controlled the PF sample flow rate and temperature to $50 \mathrm{~L} / \mathrm{min}$ and $300^{\circ} \mathrm{C}$. Samples were exposed to engine exhaust long enough to load 120,190 , or $270 \mathrm{mg}$ of particulate, corresponding to 3,5 , or $7 \mathrm{~g}$ of particulate per liter of filter (henceforth, $\mathrm{g} / \mathrm{L}$ ), respectively. The samples were shipped from the engine test facility to the evaluation laboratory packed in dry ice and stored in a freezer. The neutron images that are the primary focus of the present study were collected with uncatalyzed SiC PFs that were filled to 3,5 , or $7 \mathrm{~g} / \mathrm{L}$.

\subsection{PF Regeneration Technique and Pressure Drop}

Measurements

Due to the complexities inherent in engine experiments, we decided to conduct our PF regeneration on an automated bench-scale flow reactor system. One filter sample at a time was wrapped with fiberglass strands and loaded into a 31-mm outer diameter quartz tube (Fig. 2). The quartz tube was fitted with custom stainless steel end caps and loaded into a tube furnace (Lindberg Blue/M Mini-Mite) to control temperature. Thermocouples $(0.5-\mathrm{mm}$ diameter type K, Omega Engineering) were placed $5 \mathrm{~mm}$ upstream of the filter, in the axial midpoint of an outlet channel located near the radial filter center, and $5 \mathrm{~mm}$ downstream of the filter. System pressures were monitored with Omega Engineering PX419-030AV pressure transducers. The $6.4-\mathrm{mm}$ stainless steel lines leading to and from the reactor were maintained at $200{ }^{\circ} \mathrm{C}$ with heat tapes (Cole Parmer EW-36050-10) to prevent vapor condensation and minimize gas adsorption. Inlet gases were mixed from compressed gas cylinders or cryogenic Dewars (Air Liquide Americas, Alphagaz 1 or better purity) using mass flow controllers (MKS 1479A). For experiments with inlet gas transients, a pneumatically actuated four-way valve (Valco A24UWE) was used to direct the flow of the reactant gases 
Fig. 1 Front, middle, and rear of particulate filter, with one unit cell highlighted to show that the inlet channel is open in the front and middle but plugged in the rear. The opposite is true for the outlet channels, i.e., plugged at front and open in the rear
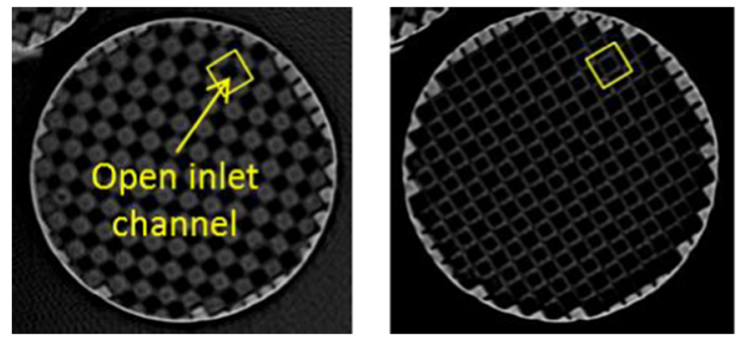

either to the reactor or to an exhaust line. A dome-loaded backpressure regulator (Equilibar EB1LF) was used to keep the backpressure on the exhaust line the same as that in the reactor, guaranteeing smooth switching operation. Water was introduced with an HPLC pump (Eldex Optos 1MP) connected to a custom-built vaporization system. Gas concentrations were measured with an MKS Multigas 2030 HS Fourier transform infrared spectroscopy (FTIR) spectrometer.

Two different types of regeneration experiments were conducted on the flow reactor. In the first set of experiments, sootloaded PFs were fully regenerated over the course of a single temperature-programmed oxidation (TPO) run. At the beginning of a TPO experiment, the PF sample was heated to $200{ }^{\circ} \mathrm{C}$ under an inert flow of $\mathrm{N}_{2}$ set to achieve a gas hourly space velocity (GHSV) of $40,000 \mathrm{~h}^{-1}$. Once the temperature was stable, the gas composition was changed to $10 \% \mathrm{O}_{2}, 5 \%$

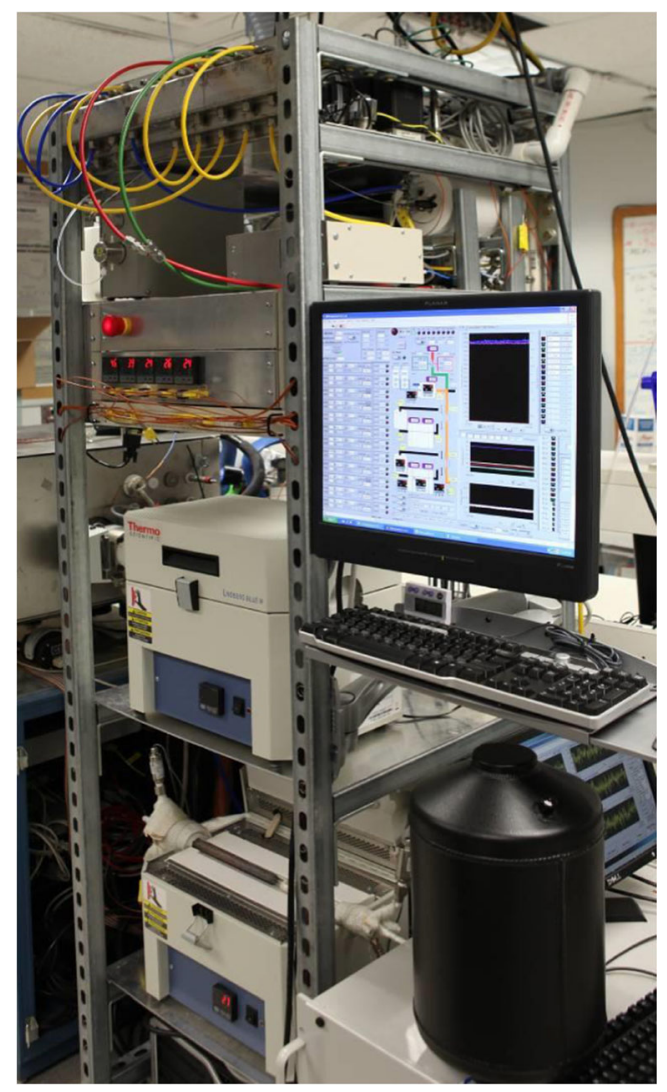

Fig. 2 Flow reactor with PF loaded in quartz reactor in bottom furnace
$\mathrm{H}_{2} \mathrm{O}$, balance $\mathrm{N}_{2}$, and the $\mathrm{PF}$ temperature was ramped from 200 to $650{ }^{\circ} \mathrm{C}$ at a rate of $2{ }^{\circ} \mathrm{C} \mathrm{min}^{-1}$. The ramp rate and final temperature were chosen to ensure complete regeneration of the PF samples by the end of the run. TPO experiments were conducted on six different $\mathrm{PF}$ samples of varying formulation loaded with $7 \mathrm{~g} / \mathrm{L}$ of particulate matter.

The second set of experiments consisted of sequential partial regenerations of the uncatalyzed SiC PFs that were used for neutron imaging. The PF sample was initially heated to $200{ }^{\circ} \mathrm{C}$ under an inert flow of $\mathrm{N}_{2}$, at a GHSV of $20,000 \mathrm{~h}^{-1}$. Once the temperature stabilized, the gas composition was changed to $10 \% \mathrm{O}_{2}, 5 \% \mathrm{H}_{2} \mathrm{O}$, balance $\mathrm{N}_{2}$, and the $\mathrm{PF}$ temperature was ramped from 200 to $500{ }^{\circ} \mathrm{C}$ at a rate of $10{ }^{\circ} \mathrm{C} \mathrm{min}{ }^{-1}$. The PF was held under this composition and temperature until the target partial regeneration threshold was exceeded, at which point, the composition was switched back to $\mathrm{N}_{2}$ and the PF was cooled back down to room temperature. Two different types of regeneration threshold were employed. For the nominal 20 and $70 \%$ regeneration cases, the $\mathrm{CO}$ and $\mathrm{CO}_{2}$ concentrations measured from the FTIR were integrated in real time to determine when the desired amount of particulate mass had been removed from the PF. While this calculation ignored noncarbon components of the particulate matter, the results below will demonstrate that counting only the carbon removed from the filter was still a reasonable approximation for total particulate mass. For the $50 \%$ regeneration cases, the reactant flows were stopped when the pressure drop across the PF sample dropped below 0.01 bar. This pressure threshold was chosen based on prior experiments that showed that the filter backpressure at $500{ }^{\circ} \mathrm{C}$ dropped to around 0.01 bar after roughly $50 \%$ of the particulate matter had been removed. Finally, since the goal of the $100 \%$ regenerations was to completely clean the filter of particulate matter, the sample temperature was ramped to $500{ }^{\circ} \mathrm{C}$, held there for $30 \mathrm{~min}$, and then ramped to $600{ }^{\circ} \mathrm{C}$ to ensure complete regeneration. The sample temperature was dropped back down to $500{ }^{\circ} \mathrm{C}$ under the reactant flows to measure the pressure drop of the clean PF.

\subsection{Neutron Imaging Facility}

The CG-1D neutron imaging beamline sits in the cold guide hall of the 85 MW High Flux Isotope Reactor (HFIR) and provides a polychromatic neutron beam with different 


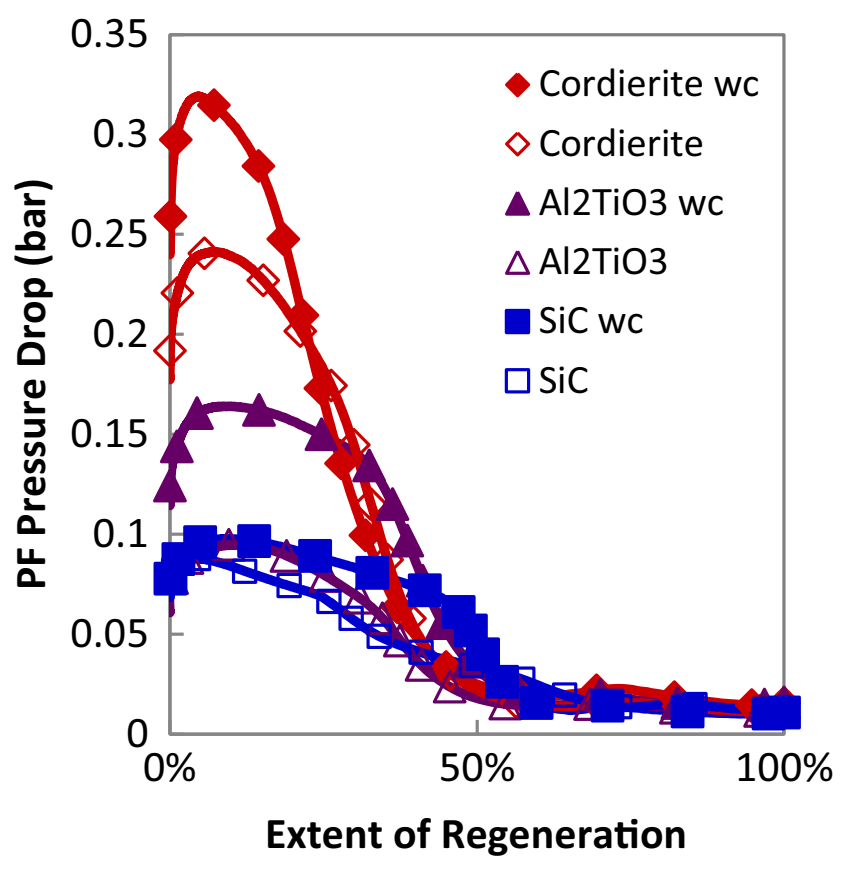

Fig. 3 Pressure drop as a function of regeneration extent for several different PF formulations with and without an oxidation catalyst washcoat (wc), all initially loaded with $7 \mathrm{~g} / \mathrm{L}$ of particulate matter. Regeneration occurred during a temperature-programmed oxidation $\left(200-650{ }^{\circ} \mathrm{C}, 2{ }^{\circ} \mathrm{C} \mathrm{min}^{-1}\right)$ under $10 \% \mathrm{O}_{2}, 5 \% \mathrm{H}_{2} \mathrm{O}$, balance $\mathrm{N}_{2}$ at a GHSV of $40,000 \mathrm{~h}^{-1}$

aperture sizes (i.e., pinhole geometry) located at the entrance of a $4.5 \mathrm{~m} \mathrm{He}$-filled flight tube. For these experiments, the beam aperture was $8 \mathrm{~mm}$ and the total flight path was $5 \mathrm{~m}$, resulting in a $L / D$ of 625 , where $L$ is the total flight path and $D$ is the diameter of the aperture. The facility provides a range of cold neutrons, most of which have a wavelength between 0.8 and $6 \AA$ (with a peak at $\sim 2.6 \AA$ ) [11]. CG-1D is equipped with a $50-\mu \mathrm{m}$-thick $\mathrm{LiF} / \mathrm{ZnS}$ scintillator and a DW936 IkonL ANDOR $^{\mathrm{TM}}$ CCD camera system. During the experiments, the neutron flux was $1 \times 10^{6} \mathrm{n} / \mathrm{cm}^{2} \mathrm{~s}^{-1}$ with a field of view of $\sim 7 \mathrm{~cm} \times 7 \mathrm{~cm}$.

2.4 Conversion of Neutron Radiographs into a Tomographic Image

A more detailed description of the approach used to convert neutron radiographs into high-contrast images can be found elsewhere [7, 12], but we offer an abbreviated description of the iterative reconstruction method here. A tomographic image can be reconstructed from a set of projection images of an object, taken at different angles, using either an analytic or an iterative algorithm. The former approach is based on the filtered back projection technique. Such algorithms are fast but tend to produce low-contrast images when the signal to noise ratio is low or when the neutron interaction with the sample is minimal; thus, the image does not have enough contrast. The latter approach is based on optimization of a criterion function that relates the fit of the reconstructed image with the given projection data. While the iterative algorithm is computationally expensive, a high-contrast image is often the result even when the count statistics are suboptimal and the number of projections is limited. As our data have intrinsically low contrast due to the low hydrogen content and the desire for a large number of projections has to be traded off against a long exposure time for each projection, we chose to implement an iterative reconstruction algorithm and use parallel computing techniques to offset the associated cost/time constraints. We refer to [12] for a review of the underlying math, and for a more intuitive description of how the images are reconstructed, please see [7].

Fig. 4 Reconstructed image of $\mathrm{SiC}$ PF filled with $7 \mathrm{~g} / \mathrm{L}$ of particulate. Area calculations using inlet and outlet channels allowed the calculation of the particulate layer thickness $\left(T_{p}\right)$ for each inlet channel
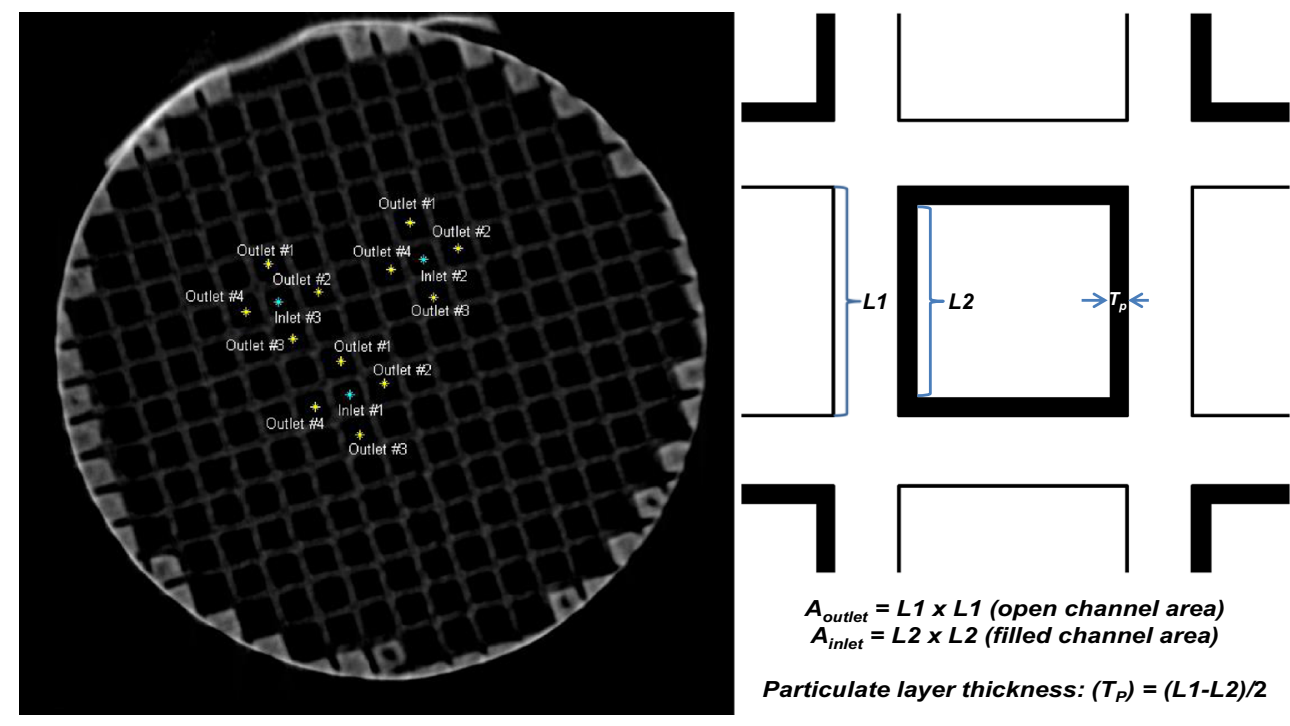


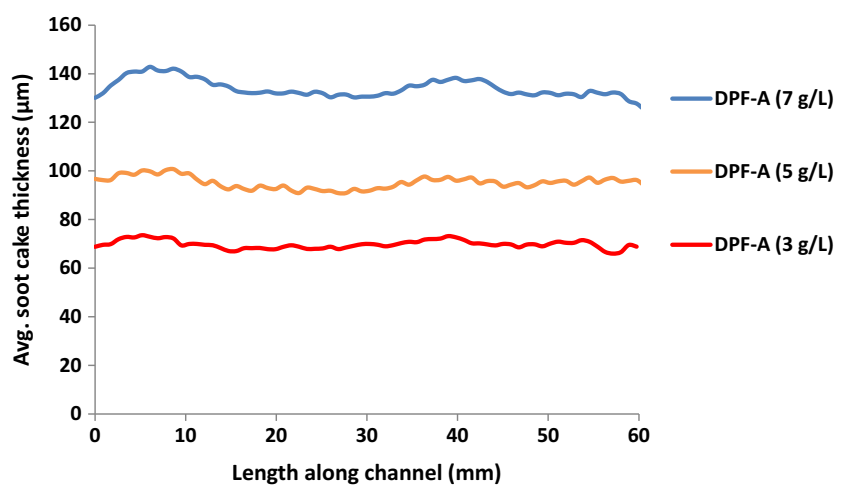

Fig. 5 The average of all channels in a given virtual slice is plotted as a function of length. The relatively flat profiles reveal an average soot cake density of 70, 96, and $131 \mu \mathrm{m}$ for the SiC PFs loaded to 3, 5, and $7 \mathrm{~g} / \mathrm{L}$

\section{Results and Discussion}

\subsection{Regeneration in the Flow Reactor}

The filter backpressure evolution during the regeneration is shown in Fig. 3 for all three filter materials both with and without an oxidation catalyst washcoat (wc). This figure shows filter pressure drop as a function of soot burnout (the fraction of the soot already oxidized) for filters loaded to $7 \mathrm{~g} / \mathrm{L}$. The fully loaded filter pressure drop changes based on the PF formulation, since the filter microstructure depends on the substrate material and the presence or absence of a catalytic wc. For all three substrate materials, adding a wc increases the filter backpressure, due to occlusion of pores in the filter wall. Interestingly, for all of the formulations, the filter pressure drop decreases to that of a clean filter after only half of the soot has been oxidized. This observation highlights the inadequacy of pressure sensors for determining filter regeneration status: the pressure sensor would indicate a complete regeneration long before all of the soot in the filter has actually been consumed. It also illustrates the complex spatial dependence of the soot oxidation process: the soot that creates most of the filter pressure drop burns out faster than the soot located elsewhere.

\subsection{Measurement of Initial Soot Layer Thickness in the Uncatalyzed SiC Filters}

As discussed above, the neutron imaging focused on a series of three different SiC PFs that were loaded to 3, 5, and $7 \mathrm{~g} / \mathrm{L}$ of particulate matter. For $\mathrm{SiC} \mathrm{PFs,} \mathrm{there} \mathrm{is} \mathrm{a} \mathrm{minimal} \mathrm{contrast}$ between the particulate and the filter wall, making it difficult to identify the transition from wall to soot cake and thus measure the particulate layer. However, the open crosssectional area of the inlet channels is distinctly less than the outlet channels for a PF loaded with soot; this is apparent in the image in Fig. 4. This enabled the use of a simple geometric formula to account for the area differences between the inlet channel and its adjacent outlet channels. Essentially, the area could be calculated for either channel, $A_{\text {inlet }}$ and $A_{\text {outlet }}$. Assuming a square geometry, a calculation of the square root of the areas gives the average length of the wall, $L 1$ for outlet and $L 2$ for inlet. From these values, the particulate layer thickness $\left(T_{\mathrm{p}}\right)$ is simply given by the following:

$T_{\mathrm{p}}=(L 1-L 2) / 2$

Applying an area calculating algorithm for each virtual slice allowed the determination of $T_{\mathrm{p}}$ for each channel. For each inlet, L1 was calculated using the mean $A_{\text {outlet }}$ of appropriate neighboring channels. For simplicity in visualizing the data, the $T_{\mathrm{p}}$ for all inlet channels was averaged over the entire slice; this allowed plotting $T_{\mathrm{p}}$ as a function of length along the channel, as shown in Fig. 5. The relatively flat profiles suggest that averaging over the entire $\mathrm{PF}$ is reasonable and reveal an average soot cake density of 70,96 , and $131 \mu \mathrm{m}$ for the $\mathrm{SiC}$ PFs loaded to 3,5 , and $7 \mathrm{~g} / \mathrm{L}$. These results support the proposed hypothesis that the soot layer is "self-leveling": as the soot layer builds and creates flow resistance, the particulate flow moves to a more open space until the resistance

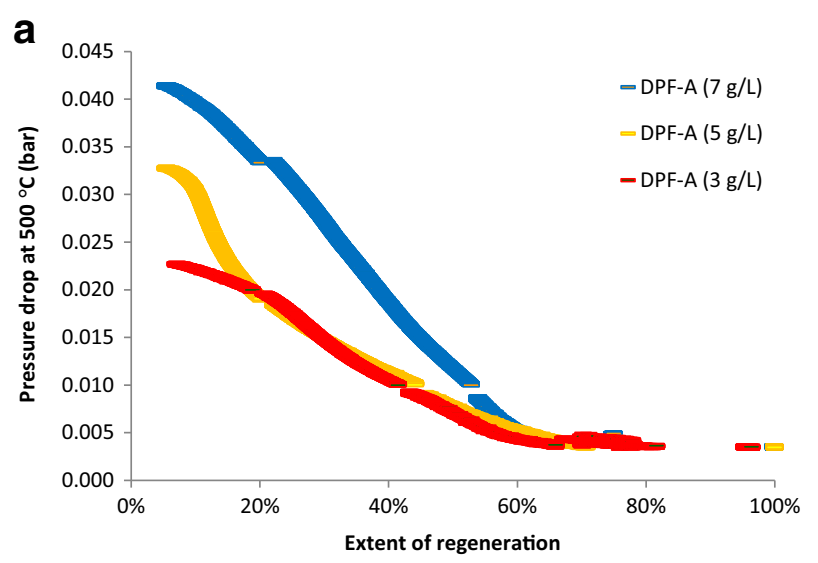

b

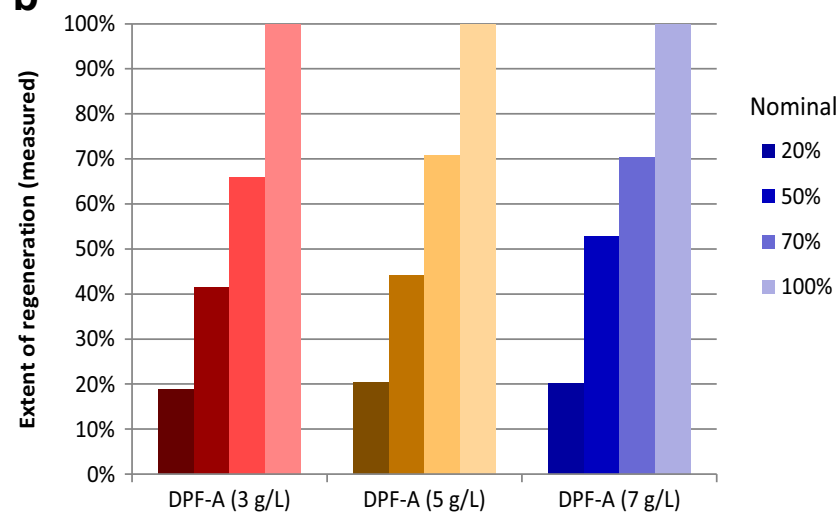

Fig. 6 a Pressure drop progression during the regeneration of the three DPFs and $\mathbf{b}$ the measured extent of reaction for each DPF and its relation to the nominal value. Reactor conditions $500{ }^{\circ} \mathrm{C}, 10 \% \mathrm{O}_{2}, 5 \% \mathrm{H}_{2} \mathrm{O}$, balance $\mathrm{N}_{2}\left(\mathrm{GHSV} 20,000 \mathrm{~h}^{-1}\right)$ 

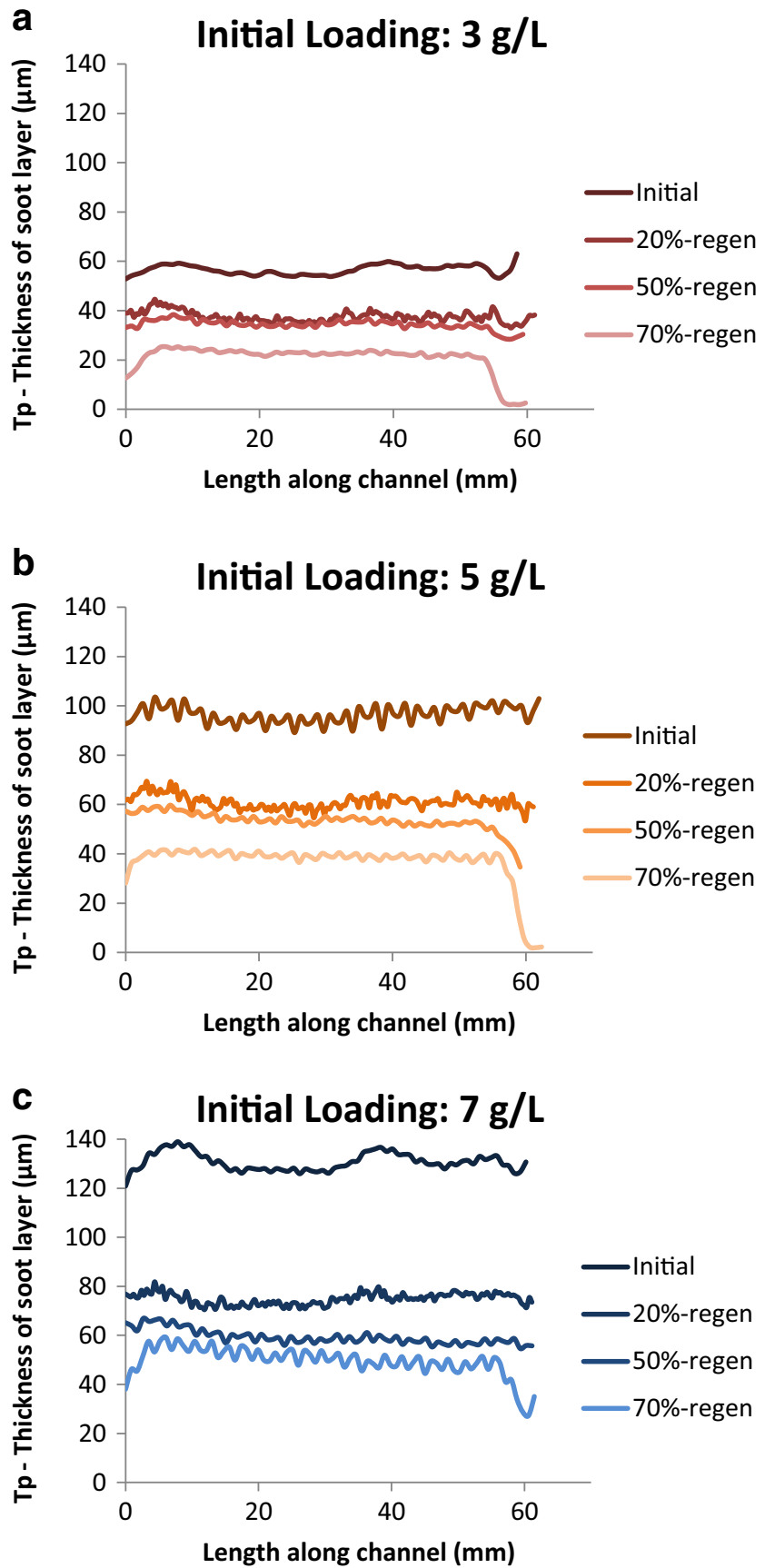

Fig. 7 The average soot cake layer thickness of all channels in a given virtual slice is plotted as a function of length for the DPFs. The samples are initially loaded to a 3 , b 5 , and c $7 \mathrm{~g} / \mathrm{L}$, followed by sequential nominal regeneration to 20,50 , and $70 \%$ levels

equilibrates, thereby resulting in a fairly even distribution of soot down the length of the filter channel.

\subsection{Particulate Layer Thickness and Density \\ During Regeneration and Conceptual Model}

After the initial imaging of the SiC PFs loaded to 3,5 , and $7 \mathrm{~g} / \mathrm{L}$, a sequential regeneration of the PFs was initiated. The target regeneration steps were nominally 20,50 , and $70 \%$ removal of the initial soot loading. As discussed in the experimental section, the $50 \%$ regeneration step was terminated when the measured pressure drop fell below 0.01 bar, which is approaching the pressure drop of a clean PF under the regeneration conditions, as it was anticipated that backpressure would drop rapidly until roughly half of the particulate had been removed. The progression of pressure drop as a function of soot loading during regeneration at $500{ }^{\circ} \mathrm{C}$ is shown in Fig. 6a. The breaks in the curves occur during the points at which the regeneration experiment was not operating at $500{ }^{\circ} \mathrm{C}$ (during heat up, for example). The 0.01-bar pressure drop threshold that was used to end the nominal $50 \%$ burnout experiment was crossed when the extent of regeneration was 41,44 , and $53 \%$ for the 3,5 , and $7 \mathrm{~g} / \mathrm{L}$ samples, respectively. This data is also represented in Fig. 6b, as the measured extent of regeneration is shown for each of the nominal points.

To help understand the physical behavior of the soot cake layer that could impart such a change in the pressure drop at $50 \%$ regeneration, neutron tomography was employed. Figure 7 shows how the measured soot cake thickness changes with the extent of reaction and along the length of the channel for each SiC PF sample. The soot cake layer decreased in thickness sharply during the initial $20 \%$ regeneration for all three samples, which is also reflected in the sharp rise in the soot cake density in Fig. 8; i.e., the thickness decreased more than would be predicted from a simple monotonic regeneration. This density is calculated as a global average of the soot cake, not the density of the soot particles. At $50 \%$ regeneration, the soot cake thickness has not changed significantly even though the amount of particulate removed from the filter has more than doubled since the end of the first step. As the samples are regenerated to $70 \%$, the particulate layer thickness decreases, but the total magnitude of the decrease between 20 and $70 \%$ regeneration is not as significant as it was in the first $20 \%$ regeneration (Fig. 7). These observations are also highlighted in the density calculations in Fig. 8: the soot

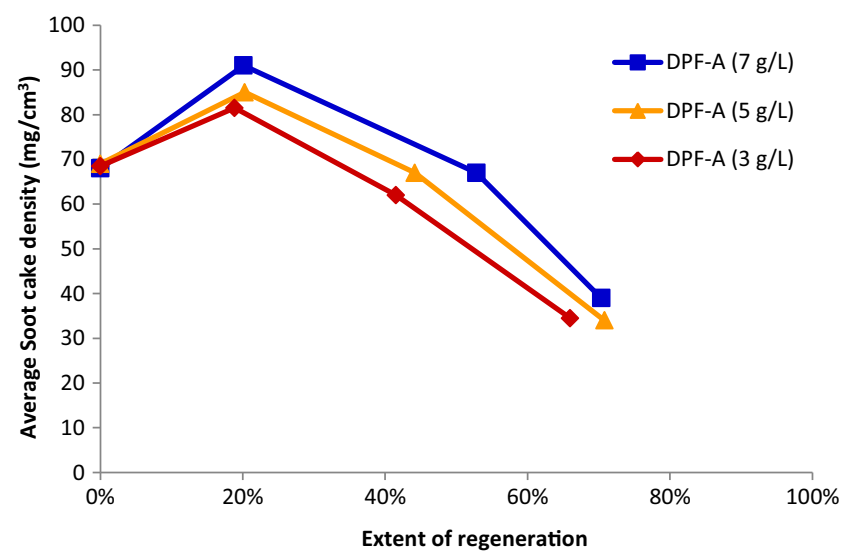

Fig. 8 Calculated values of the average soot cake density for the profiles in Fig. 7 
Fig 9 Conceptual model of progression during soot cake layer during regeneration

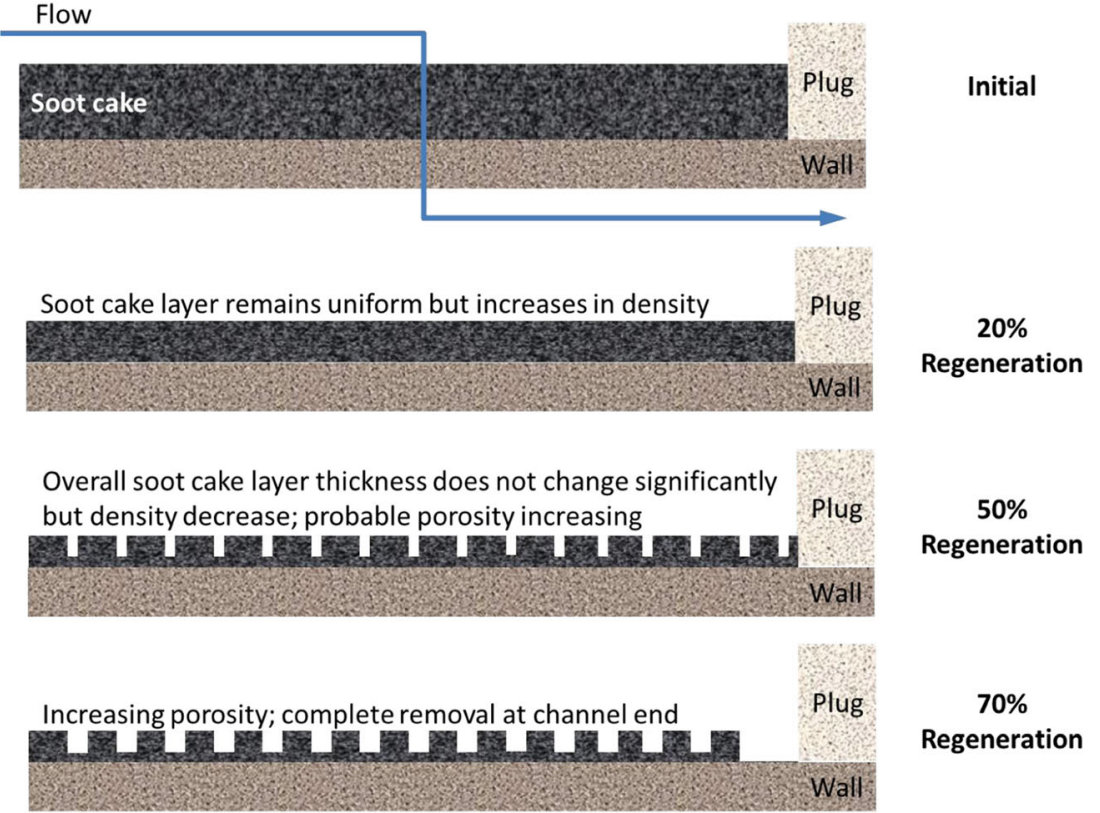

cake density increases in the first step and then decreases sharply in subsequent steps as the volume of particulate does not decrease as fast as the mass. Additionally, it is observed that the first area of the PFs that is fully regenerated is at the rear of the inlet channels; signs of this local soot removal are seen in all three samples.

These observations have led to a conceptual model of the regeneration process, as illustrated in Fig. 9. A uniform particulate layer is observed for the initially loaded sample. After regenerating $20 \%$ of the sample, the soot cake layer thickness decreases much faster than can be explained by a simple removal of the top layers of soot. Instead, there appears to be a significant densification of the soot layer during the early phases of regeneration. At $50 \%$ regeneration, average soot cake density decreases sharply as pores open in the layer; this process continues through $70 \%$ regeneration. This opening of pores in the soot cake provides an explanation for why the measured pressure drop approaches that of a clean PF after roughly $50 \%$ regeneration. Other studies in the recent past have employed optical techniques to observe the regeneration process [3-5]. Although less quantitative than the approach employed here, similar observations were noted. In particular, large pores opening up in the soot cake are observed after significant regeneration has occurred. From the top down view employed by the optical studies, it is difficult to determine if the densification is occurring; thus, the quantitative results described here identify a key phenomenon. Other earlier soot cake oxidation studies that offer some support of this conceptual model identified the resistance to flow decreases sharply prior to full regeneration $[2,13]$.

Another feature of note is that the PF is fully regenerated at the rear of the inlet channels first. This is clearly seen in the 3 and $5 \mathrm{~g} / \mathrm{L}$ samples at $70 \%$ regeneration; the $7 \mathrm{~g} / \mathrm{L}$ sample is well on its way to a similar localized complete regeneration. This is likely due to the more turbulent nature of the flow up against the plug at the end of the inlet channel. Gas flow would be expected to swirl in the rear of the DPF and interact more frequently with the walls; thus, the earlier regeneration occurs here first. This flow effect is also discussed in the work by Sappok et al. where the radial velocity is predicted to increase at the rear compared to the front and middle [4]. Complete regeneration occurring first at the outlet in our study does differ from their conceptual model; however, the focus of their study was on the nature of ash deposits and flow and with a high amount of ash blocking access to the soot in the rear. In the presence of ash, this soot would not likely to regenerate first, but in our clean PFs without ash blocking access, we observe different behavior and thus propose a modified conceptual model.

Acknowledgments This research was sponsored by the US Department of Energy, Office of Energy Efficiency and Renewable Energy, Vehicle Technologies Program under contract DE-AC05-00OR22725 with the US Department of Energy. Additionally, a portion of this research at ORNL's High Flux Isotope Reactor was sponsored by the Scientific User Facilities Division, Office of Basic Energy Sciences, US Department of Energy. Finally, we would like to express our gratitude to Vadim Strots, Brad Adelman, and Ed Derybowski of Navistar, Inc., who provided the soot-loaded $\mathrm{PF}$ samples and allowed us to image the $\mathrm{SiC}$ particulate filters used in this study.

\section{References}

1. Price, K., Bailey, O.:"'Observations on the performance and control of 2008 Dodge Diesel Ram emissions system over 30,000 miles," 12th Crosscut Lean Emissions Reduction Simulation Workshop, Dearborn, MI, April 30, (2009) 
2. Konstandopoulos, A. G., Kostoglou, M., Skaperdas E., Papaioannou E., Zarvalis, D., Kladopoulou E.: "Fundamental studies of diesel particulate filters: transient loading, regeneration and aging," SAE Technical Paper Series 2000-01-1016 1 (2000)

3. Sappok, A., Govani, I., Kamp, C., Wang, Y., Wong, V.: In-Situ Optical Analysis of Ash Formation and Transport in Diesel Particulate Filters During Active and Passive DPF Regeneration Processes. SAE Int. J. Fuels Lubr. 6(2), 336-349 (2013)

4. Sappok, A., Wang, Y., Wang, R.-Q., Kamp, C., Wong, V.: Theoretical and Experimental Analysis of Ash Accumulation and Mobility in Ceramic Exhaust Particulate Filters and Potential for Improved Ash Management. SAE Int. J. Fuels Lubr. 7(2), 511-524 (2014)

5. Choi, S., Lee K.:"Detailed Investigation of Soot Deposition and Oxidation Characteristics in a Diesel Particulate Filter Using Optical Visualization," SAE Technical Paper Series 2013-01-0528 1 (2013)

6. Strzelec, A., Bilheux H. Z., Finney, C. E. A., Daw, C. S., Foster, D. E., Rutland C. J., Schillinger B., Schulz M.:"Neutron imaging of diesel particulate filters," SAE Technical Paper Series 2009-01-2735 (2009) 1.

7. Toops, T.J., Bilheux, H.Z., Voisin, S., Gregor, J., Walker, L., Strzelec, A., Finney, C.E.A., Pihl, J.A.: Neutron tomography of particulate filters: A non-destructive investigation tool for applied and industrial research. Nucl Inst Met Phys Res Sec A 729, 581-588 (2013)
8. Ismail, B., Ewing, D., Chang, J.-S., Cotton, J.S.: Development of a non-destructive neutron radiography technique to measure the threedimensional soot deposition profiles in diesel engine exhaust systems. J Aerosol Sci 35(10), 1275 (2004)

9. Kardjilov, N., Hilger, A., Manke, I., Strobl, M., Treimer, W., Banhart, J.: Industrial applications at the new cold neutron radiography and tomography facility of the HMI. Nucl Inst Met Phys Res A 542(1-3), 16-21 (2005)

10. Strobl, M., Treimer, W.,Ritzoulis, C., Wagh, A.G., Abbas, S., Manke, I, "The new V12 ultra-small-angle neutron scattering and tomography instrument at the Hahn-Meitner Institut," Journal of Applied Crystallography 40:Supplement (2007) S463

11. Kang, M., Bilheux, H.Z., Voisin, S., Cheng, C.L., Perfect, E., Horita, J., Warren, J.M.: Water calibration measurements for neutron radiography: Application to water content quantification in porous media. Nucl Inst Met Phys Res A 708, 24 (2013)

12. Tobin, K., Bingham, P., Gregor, J.: Mathematics of Neutron Imaging. In: Anderson, I., McGreevy, R., and Bilheux H.Z. (eds.), Neutron Imaging and Applications, Springer, pp 109-128 (2009)

13. Konstandopoulos, A.G., Kostoglou, V.M., Kladopoulou, N.E.: "Progress in diesel particulate filter simulation," SAE Technical Paper Series 2005-01-0946 (2005) 1 